\title{
Catalyzing the scale-up of community-based primary healthcare in a rural impoverished region of northern Ghana
}

\author{
John Koku Awoonor-Williams ${ }^{1,2,3 *, \dagger}$, James F. Phillips $^{4,+}$ and \\ Ayaga A. Bawah ${ }^{4, \S}$ \\ ${ }^{1}$ Ghana Health Service PMB, Bolgatanga, Upper East Region, Ghana \\ ${ }^{2}$ Swiss Tropical and Public Health Institute, Basel, Switzerland \\ ${ }^{3}$ University of Basel, Peterplatz 4003, Basel, Switzerland \\ ${ }^{4}$ Mailman School of Public Health, Columbia University, New York, New York, USA
}

\begin{abstract}
SUMMARY
Ghana's Community-based Health Planning and Services (CHPS) initiative develops accessible healthcare with participatory community support, using strategies developed and tested by a project of the Navrongo Health Research Centre. In 1996, the project was expanded to a district-wide four-celled trial. In response to evidence that strategies could reduce fertility and childhood mortality, a replication project was launched to develop methods for scaleup. Based on experience gained, CHPS scale-up was launched in 2000. Although CHPS now reaches all of Ghana's districts, the pace of scale-up within districts has been slow. In response, the Ministry of Health conducted a review of factors that constrain CHPS scaleup and problems that detract from its original evidence-based design. To resolve problems that were identified, a project was launched in 2010 to test means of accelerating CHPS scale-up and expand its range of care. Known as the Ghana Essential Health Interventions Program (GEHIP), the project provided catalytic revenue to four treatment district managers for 3 years, in conjunction with implementation of strategies for comprehensive leadership development and community partnership. Monitoring systems were developed to gauge CHPS coverage time trends in all nine study districts. GEHIP successfully accelerated CHPS implementation, producing $100 \%$ of its targeted community coverage within 5 years of implementation. Coverage in comparison districts also improved. However, the rate of coverage and per cent of the population reached by CHPS in comparison districts was only half that of GEHIP districts. GEHIP success in completing CHPS coverage represents the initial stage of a national program for strengthening community health systems in Ghana. Copyright (c) 2015 John Wiley \& Sons, Ltd.
\end{abstract}

KEY WORDS: Ghana; community-based primary healthcare; scale-up; health system strengthening

\footnotetext{
*Correspondence to: J. K. Awoonor-Williams, Ghana Health Service PMB, Bolgatanga, Upper East Region, Ghana. E-mail: kawoonor@gmail.com

${ }^{\dagger}$ Regional Health Directorate.

${ }^{\dagger}$ Professor.

${ }^{\S}$ Assistant Professor.
}

Copyright (C) 2015 John Wiley \& Sons, Ltd. 


\section{INTRODUCTION}

The implementation of community-based primary healthcare programs is being expanded throughout Africa (Freeman et al., 2009; World Bank, 2005; Perry et al., 2014). Yet, clinic-focused services remain the mainstay of most community-based primary healthcare service designs, despite several convincing demonstrations that community-based operations can be more effective if low-cost accessible essential health services are augmented with provision for active doorstep services (Perry et al., 2003; McCabe et al., 2012). While pilot projects and special studies are often evaluated, factors that constrain the process of scale-up are rarely the subject of direct investigation; implementation research focused on accelerating scale-up is rarer still. Yet, researching the implementation of scale-up is typically needed. Reviews of scale-up have cited constraints to effective utilization of proven innovations, either because original pilot or experimental project service models are diluted or compromised with scale-up or because the pace of organizational change is constrained by problems.

Challenges to effective scale-up are particularly prominent for projects focused on community-based primary healthcare. Providing community-based care is more than simply constructing and staffing village health posts. The process of supplementing fixed facility care with community-based outreach encounters requires the creation of a cadre of community-based workers who are championed by local leaders, welcomed by households served, and supported by the implementation of logistics, supervision and leadership of the health system at large. But the organizational challenges associated with community-based primary healthcare often require new national policies and manpower plans, incremental resources, and actions that decentralize planning at each organizational level down to the periphery of service operations, changes that invite complex and often unanticipated challenges (Binswanger and Aiyar, 2003; Simmons and Shiffman, 2005).

These challenges have been evident in Ghana. Although policy commitment to achieving community-based primary healthcare in Ghana began in the early 1980s, impetus for this goal commenced in the 1990s with a continuous and growing role of implementation research that continues to date (Nyonator et al., 2005b; Awoonor-Williams et al., 2013c). As in many countries, by the early 1990s, achieving accessible care was a pillar of policy in Ghana, yet the specific means of achieving this goal remained unclear. Whereas research had described the nature of problems and established the rationale for national action, little evidence existed to guide program development (Nyonator et al., 2005a).

An evidence-guided community health system program that was associated with considerable success as an approach to developing large-scale primary healthcare implementation was developed. We direct particular attention to an implementation research initiative that was directed to clarifying factors that have constrained the scale-up of this proven approach to community-based primary healthcare. Despite compelling evidence that its strategies could enable Ghana to achieve national Millennium Development Goals, the strategy has been slow to scale-up (Nyonator et al., 2011). We review results achieved by a project that has responded to scaleup challenges, accelerated implementation and provided a body of evidence that 
could set the stage for reforming national community-based primary healthcare implementation (Awoonor-Williams et al., 2013a, 2013b).

\section{The Community-based Health Planning and Services initiative}

Community-based primary healthcare in Ghana is the outcome of a national program for reorienting services from district hospitals and sub-district clinics to convenient community locations. Launched as a national policy promulgated in 1999 and implemented in 2000 as a national program, the approach is termed the Community-based Health Planning and Services (CHPS) Initiative. Grounded in overlapping phases that commenced in 1994 and have unfolded over time, each phase has involved research activities and implementation in response to evidence, guided by phases portrayed in Figure 1 (Nyonator et al., 2008).

Phase 1: participatory planning. In phase 1, a three-village micro-pilot extended over an 18-month period from 1994 to 1996. Qualitative research was conducted in combination with primary healthcare service delivery with the goal of adapting activities to the social context (Adongo et al., 1997). Services were introduced in conjunction with interactions with individuals and groups about matters that are strongly influenced by social norms and institutions, using methods that have been applied widely in other contexts (Sarri and Hasenfeld, 1978). Qualitative techniques elicited community-member perspectives on ways to address gender problems (Bawah et al., 1999), with particular focus on customs that restrict women's autonomy to seek healthcare (Ngom et al., 2003). Community advice was translated into strategies for engaging the support and participation of men in family planning

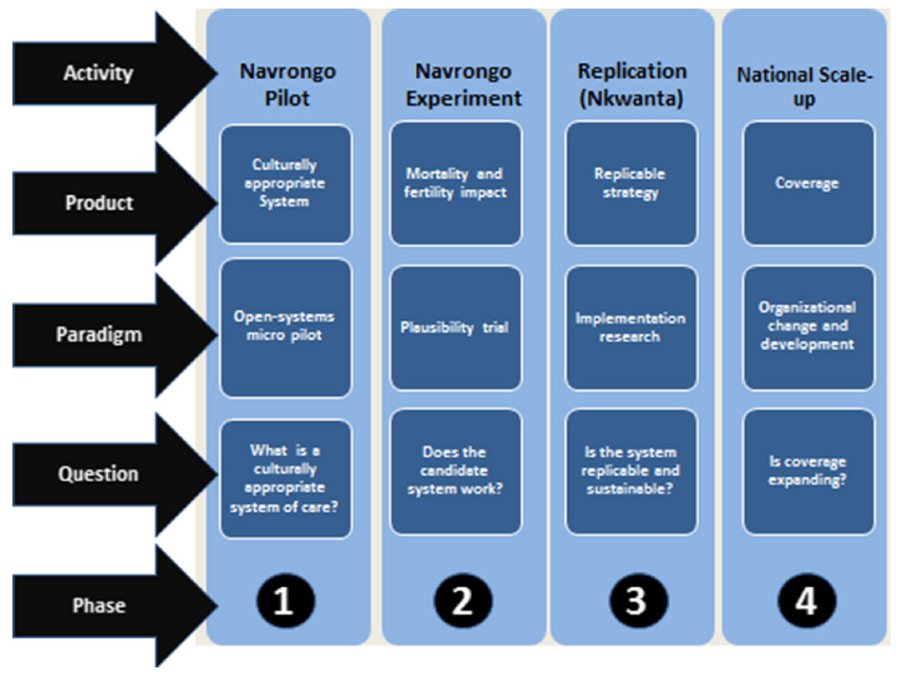

Source: Nyonator, et al. 2005a

Figure 1. Phases in the development of the Community-based Health Planning and Services initiative. Source: Nyonator et al., 2005a 
(Adongo et al., 2014) and establishing practical means of ensuring worker accountability to community members and traditional leaders (Nazzar et al., 1995).

Phase 2: a controlled plausibility trial. Strategic details of primary healthcare services developed in phase 1 were tested in a phase 2 plausibility design (Binka et al., 1995) in which communities were grouped into two "arms" of service intervention:

The zurugelu (togetherness) arm involved mobilizing cultural resources of chieftaincy, social networks, village gatherings, voluntary activities and community support to provide gender-based outreach care. Closely resembling the UNICEFsponsored "Bamako Initiative," this arm of the project had mechanisms for recovering the cost of essential drugs, and supervision and support for volunteers that included the provision of bicycles, start-up kits of essential drugs and training in basic referral care (Knippenberg et al., 1990).

The "community health officer" arm of the experiment reoriented existing paid nurses to conduct village-based service delivery. Nurses entering the program had completed 18 months of training in basic curative health services and public health practice that included childhood immunization and family planning. Reorientation to community-based work involved 6 additional weeks of intensive in-service training in methods of community engagement, outreach organization, and community healthcare planning. Communities were responsible for the maintenance and security of the compound, nurses' daily living needs and the costs of essential drugs. Nurses were provided with pharmaceutical kits, essential clinical equipment, salaries and motorcycles. Services were provided during household visits, augmented with daily care at the community health compound. Where volunteers were available, community nurses were designated as their supervisors.

Because these two arms of the intervention strategy could be implemented independently, jointly or not at all, a four-celled design was specified, exposing communities to alternative primary healthcare service provision strategies.

Results demonstrated that child mortality declined by half in 5 years wherever nurses were assigned but that the zurugelu approach had no fertility or mortality impact (Binka et al., 2007; Pence et al., 2007). Somewhat surprisingly, posting nurses to communities had no impact on family planning uptake or fertility unless their presence was combined with zurugelu volunteer deployment. To achieve national reproductive and child health goals, a combined zurugelu plus nurse deployment strategy was indicated (Debpuur et al., 2002; Phillips et al., 2006; Binka et al., 2007).

Phase 3: Nkwanta validation and replication research. In 1998, a National Health Forum was convened for all district and regional health system managers to review the initial Navrongo results. Debate ensued over the national relevance of results and the feasibility of changing routine district operations to the Navrongo approach. Participants argued that the logistics required would incur unsustainable costs for monitoring and supervision, equipment and health post construction. Many viewed community mobilization as a potential risk that could raise community expectations for levels of service intensity could not be met (Awoonor-Williams et al., 2010, 2013b, 2013c). 
In response to this controversy, a participating team from Nkwanta District of the Volta region launched an implementation pilot to test practical means of adapting the Navrongo model to local circumstances and, in the process, clarify milestones and procedures for scaling up Navrongo results. When this replication trial succeeded, a second National Health Forum was convened in 1999 to announce results, build consensus for a national program, and launch replication projects on the Nkwanta model in each of Ghana's eight other regions. Once pilots were functioning within these "lead districts" of each region, inter-district exchanges were convened to catalyze the scaling up of operations elsewhere, setting the stage for national implementation of community-based primary healthcare in phase 4 (Nyonator et al., 2008, 2005a, 2005b). Nkwanta thereby catalyzed the national scaling-up process by showing that the transfer of a service model from a research project to a district health service operation was feasible, by clarifying the essential milestones and resources for implementing the approach in a non-research setting, and by providing a learning locality for transferring the Navrongo approach to lead districts dispersed throughout the country.

The phase 4: national expansion. Phases 1 to 3 led to a program for scaling up a service model that translates lessons from Kassena-Nankana and Nkwanta districts into a national program for healthcare reform, as illustrated by the maps in Figure 2. By mid-2008, every region had some CHPS activity, and most districts had some degree of community-based primary healthcare coverage. Observation and monitoring showed that CHPS spread most rapidly in districts where pilots had been launched, suggesting that scale-up followed patterns of change that were characteristic of a diffusion process (Rogers, 1962). As Figure 2 shows, this process was more intense in the Upper East and Upper West Regions than in the more populous regions of central and coastal Ghana. And variance in coverage was pronounced, with some districts

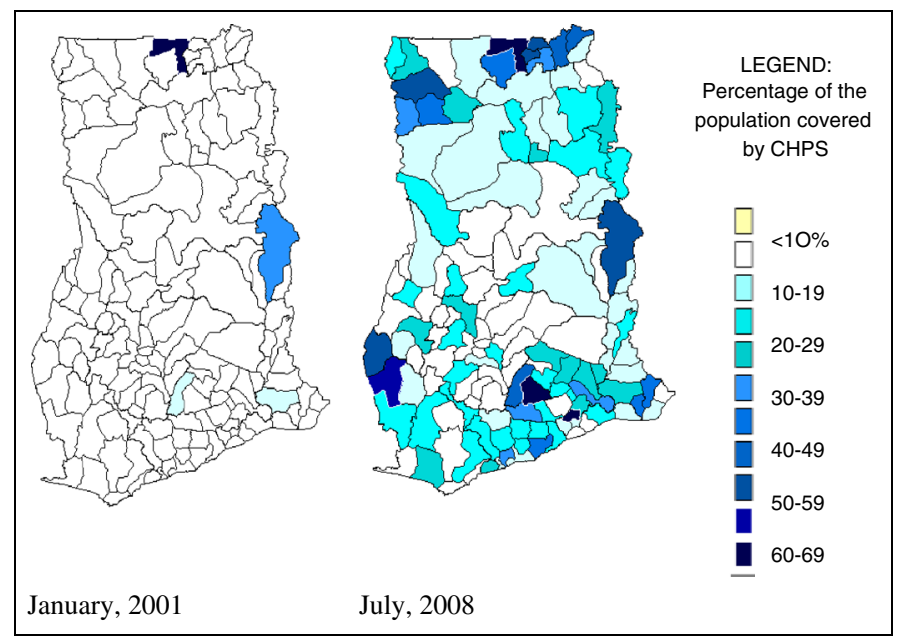

Figure 2. The geographic density of Community-based Health Planning and Services (CHPS) coverage by district, January 2001 and July 2008 
achieving advanced implementation while others making little progress at all. The national trend in the population covered by community-based care was unacceptably slow, reaching only $10 \%$ of the population covered by mid-2008. If the rate of coverage up to 2008 was projected forward, achieving the goal of universal health coverage would require nearly 50 years of program effort. Clearly, action was needed to diagnose problems with scale-up and expedite progress.

\section{THE GHANA ESSENTIAL HEALTH INTERVENTIONS PROGRAM}

\section{Factors constraining Community-based Health Planning and Services scale-up}

The slow progress with CHPS implementation in most of Ghana, with the relatively rapid increase in Ghana's two poorest, most remote and most health-deprived northern regions, prompted the Ministry of Health $(\mathrm{MOH})$ to sponsor a review of the determinants of regional and district variance in CHPS scale-up performance (Binka et al., 2009; Ministry of Health, 2009). Through comparative review of management opinion in advanced versus constrained implementation regions, the review identified factors that have constrained CHPS implementation. In response to findings from this review, the Ghana Health Service (GHS), the Mailman School of Public Health and the University of Ghana formed a partnership for testing health systems solutions to problems constraining CHPS scale-up in a 6-year implementation research trial for gauging the impact of a package of system strengthening activities on childhood survival and fertility. This experimental initiative for testing ways to improve and accelerate CHPS scale-up is known as the Ghana Essential Health Interventions Program (GEHIP) (Awoonor-Williams et al., 2013a).

The systems problems and sets of interventions that emerged from the GEHIP diagnostic appraisal process are arrayed in column 1 of Table 1 according to their relevance to six "pillars" of essential components of any functioning health systems (World Health Organization, 2007). GEHIP is a project that is designed to strengthen district systems in ways that will accelerate CHPS scale-up and improve the quality of community-based primary healthcare services. Systems constraints to CHPS scale-up were the focus of a program of intervention that has spanned the WHO six pillars, with particular attention to the roles and functions of frontline workers that could be improved by developing implementation capabilities of "District Health Management Teams" (DHMT), as summarized in the right-hand column of Table 1. Beginning in 2010, GEHIP was implemented in four districts of the Upper East Region as a plausibility trial on systems strengthening, with intervention and comparison districts located in the most impoverished of Ghana's 10 regions. Five comparison districts serve as a control, with monitoring designed to record CHPS implementation progress. A baseline and end-of-program of multi-level cluster survey research will assess the impact of GEHIP on parental health-seeking behavior, childhood survival and fertility.

Ensuring access to essential services provided by a trained and knowledgeable workforce. District managers are often reluctant to launch programs that they 
Table 1. Summary of usual CHPS strategies and GEHIP health system strengthening interventions

\begin{tabular}{|c|c|c|}
\hline $\begin{array}{l}\text { Type of health } \\
\text { system } \\
\text { component }\end{array}$ & $\begin{array}{l}\text { Current Community } \\
\text { Health Service } \\
\text { strategy }\end{array}$ & $\begin{array}{c}\text { GEHIP intervention } \\
\text { additions for strengthening } \\
\text { Ghana Health Service strategies }\end{array}$ \\
\hline $\begin{array}{l}\text { Essential } \\
\text { services }\end{array}$ & $\begin{array}{l}\text { Community Health } \\
\text { Officer (CHO) } \\
\text { provided IMCI, } \\
\text { antenatal care \& } \\
\text { family planning. }\end{array}$ & $\begin{array}{l}\text { Improving community-based services. } \\
\text { Frontline workers are trained and } \\
\text { equipped for saving newborn lives by } \\
\text { - Providing affordable equipment and } \\
\text { information systems with organizational } \\
\text { strategies for covering referral costs that } \\
\text { are not addressed by the national health } \\
\text { insurance system. } \\
\text { - improving emergency management } \\
\text { capacity: GEHIP trained frontline } \\
\text { workers in triage and emergency } \\
\text { management to prevent neonatal } \\
\text { mortality. }\end{array}$ \\
\hline $\begin{array}{l}\text { Essential } \\
\text { personnel }\end{array}$ & $\begin{array}{l}\text { CHOs trained to } \\
\text { provide primary } \\
\text { health care, volunteers } \\
\text { focused on health } \\
\text { promotion. }\end{array}$ & $\begin{array}{l}\text { Developing service quality by launching } \\
\text { health and mortality audit procedures and } \\
\text { responding to highlighted areas } \\
\text { necessitating clinical care improvements } \\
\text { to include. } \\
\text { - Essential emergency newborn care by } \\
\text { midwives and community workers in risk } \\
\text { identification \& triage, resuscitation, } \\
\text { community engaged kangaroo mother-care, } \\
\text { and other newborn care interventions. } \\
\text { - Expanding volunteer skills: in the } \\
\text { management of childhood illness. }\end{array}$ \\
\hline $\begin{array}{l}\text { Information for } \\
\text { decision-making }\end{array}$ & $\begin{array}{l}\text { Complex paper } \\
\text { registers without } \\
\text { provision for } \\
\text { feedback }\end{array}$ & $\begin{array}{l}\text { Reforming information systems for } \\
\text { decision-making by } \\
\text { - Simplifying information tools. for } \\
\text { frontline workers, improving data } \\
\text { utilization procedures, and supporting } \\
\text { supervisory decision-making. } \\
\text { - Knowledge management for decision- } \\
\text { makers. which compiles and disseminates } \\
\text { lessons learned to managers. }\end{array}$ \\
\hline $\begin{array}{l}\text { Provision of } \\
\text { drugs logistics }\end{array}$ & $\begin{array}{l}\text { Fees for family } \\
\text { planning supplies }\end{array}$ & $\begin{array}{l}\text { Ensuring access to essential equipment } \\
\text { and supplies. Health information tools } \\
\text { monitor access to essential equipment } \\
\text { and ensure essential supply and logistics } \\
\text { needs. }\end{array}$ \\
\hline $\begin{array}{l}\text { Resources, } \\
\text { budgeting \& } \\
\text { planning }\end{array}$ & $\begin{array}{l}\text { Annual budgeting; } \\
\text { health sector } \\
\text { financing }\end{array}$ & $\begin{array}{l}\text { Building district capacity for budgeting } \\
\text { and planning by developing a tool for the } \\
\text { allocation of resources according to actual } \\
\text { need so that budgeting is link to the } \\
\text { relative burden of disease benefits } \\
\text { associated with investment in alternative } \\
\text { strategies for health care. }\end{array}$ \\
\hline
\end{tabular}

(Continues) 
Table 1. (Continued)

\begin{tabular}{lll}
\hline $\begin{array}{l}\text { Type of health } \\
\text { system } \\
\text { component }\end{array}$ & $\begin{array}{c}\text { Current Community } \\
\text { Health Service } \\
\text { strategy }\end{array}$ & $\begin{array}{c}\text { GEHIP intervention } \\
\text { additions for strengthening } \\
\text { Ghana Health Service strategies }\end{array}$ \\
\hline $\begin{array}{l}\text { Leadership, } \\
\text { governance, and } \\
\text { accountability }\end{array}$ & $\begin{array}{l}\text { Leadership training } \\
\text { through workshops }\end{array}$ & $\begin{array}{l}\text { Strengthening leadership with } \\
\text { demonstration strategies for engaging } \\
\text { teams of political, traditional and health } \\
\text { system leadership into a system of } \\
\text { collaborative observation, participatory } \\
\text { problem solving and peer learning with a } \\
\text { target on expanding development sector } \\
\text { investment in CHPS scale-up. }\end{array}$ \\
\hline
\end{tabular}

GEHIP, Ghana Essential Health Interventions Program; IMCI, Integrated Management of Childhood Illness; CHPS, Community-based Health Planning and Services.

believe will require technical skills that are not yet available or activities that incur costs that the GHS or the National Health Insurance Scheme (NHIS) does not adequately finance (Nyonator et al., 2005b). The most critical aspect of access, however, is the availability of community-based care and effective services. But, even where CHPS is available, critical deficiencies arise. In particular, the NHIS has yet to cover the cost of emergency transport, and most communities have no system emergency obstetric and neonatal care (Baiden et al., 2006). Telecommunication and infrastructural problems, chronic supply chain bottlenecks, inadequate protocols for treatment of obstetric and neonatal emergencies, constrained systems of transportation and referral, and limited staff dedicated to the provision of essential care functions. Moreover, community health officers lack skills to manage normal deliveries and provide referral effectively (Awoonor-Williams et al., 2015).

Although policy guidelines aim to support facility-based delivery by providing cost-free midwifery care, the transportation costs of emergency or routine referral are not covered by the NHIS. Problems associated with home delivery persist (Awoonor-Williams and Baynes, 2013a, 2014). Barriers to the effective implementation of primary healthcare in general concatenate in ways that compound problems associated with CHPS scale-up. Skill gaps stemming from limitation of the nurse training program confront nurses with technical challenges upon their deployment. In particular, CHPS implementation is hampered by the lack of midwifery training, lack of training in emergency management and triage, and lack of participatory planning training for implementing community coordination and village diplomacy.

As a component of its initial response to gaps in essential services, GEHIP implemented a system of mortality audits to provide regional health managers with rapid feedback on preventable maternal and neonatal risks (Awoonor-Williams et al., 2015). In response to evidence that asphyxia was a prominent contributor to excess mortality, all frontline workers were trained in resuscitation management, referral services and essential emergency management. A scheme of community-engaged emergency information management, logistics and referral was piloted and 
implemented in all GEHIP districts, in conjunction with the retraining of all frontline workers in the WHO-recommended "Integrated Management of Childhood Illness" (World Health Organization, 2005). Particular attention was directed to improving the role and capabilities of volunteers in the provision of Integrated Management of Childhood Illness.

Baseline GEHIP research on worker time use showed that information management occupies more frontline work time than effort expended on care itself (Frimpong et al., 2011). Frontline care workers were obligated to maintain an unwieldy array of 27 registers each month. GEHIP streamlined this operation to five registers and improved information feedback to supervisors so that information captured by workers could actually be used to support their functions.

In summary, baseline research found that CHPS is not only failing to scale-up, as a program of service implementation, but was also failing to achieve its life-saving potential. GEHIP responded by targeting its frontline worker interventions on the most pressing contributing factors to this set of problems.

Developing systems of information for decision-making, managing essential resources, plans and budgets, and developing leadership and governance. Resources for primary healthcare in Ghana remain severely constrained. Yet budget lines for personnel, fuel, pharmaceutical costs and other critical requirements of primary healthcare are somewhat manageable once district managers are clear about operational goals and challenges, and running costs of services, supplies, fuel and salaries once operations are established and DHMT undertake financial planning and program implementation for such ongoing costs.

Despite this managerial flexibility for planning routine operating budgets, scalingup CHPS incurs start-up expenses that have no specified GHS budget line and, therefore, no mechanism for budgetary flexibility to be implemented. Expansion of costs for essential equipment, such as bicycles and motorbikes, and the start-up cost of constructing CHPS community health posts are not routine cost items that GHS district managers can add to routine budgets. Lacking practical experience with managing these CHPS start-up budgetary requirements, health managers not only fear the unknown but also are reluctant to engage in activities that could create grassroots political pressure if the cost of building health posts, purchasing equipment and implementing care is unsustainable. Indeed, the original Navrongo project incurred incremental costs amounting to $\$ 2.92$ per capita for essential equipment and facility start-up needs. But lacking a routine budget line for such costs in the national plan for earmarking resources for such CHPS implementation start-up costs severely constrained commitment to launch the program.

The CHPS implementation budget gap problem has been compounded by the introduction of the NHIS in 2008. The NHIS reimburses health providers for clinical services delivered but provides no support for community activities, referral costs or CHPS start-up expenses. As a scheme that reimburses district budgets for clinical services, the NHIS has driven CHPS into the mode of becoming a community clinicbased program for curative treatment, to the detriment of preventive care, family planning, community engagement and promotional aspects of primary care. 
To catalyze a process of reforming budgeting and developing leadership, GEHIP sets aside supplemental district funds in the amount of $\$ 0.85$ per capita per year in the four experimental districts for 4 years. This investment supplemented routine primary healthcare revenue amounting to $\$ 14$ per capita. Committed to the health budget as a flexible fund, systems change demonstration was designed to implement strategies for connecting DHMT, district political figures and community leaders into a collaborative leadership system for implementing CHPS. As a practical process, this involved implementing community-engaged celebration of implementation milestones and other activities for connecting traditional leaders and grassroots politicians through community celebration of the completion of implementation milestones. The process was designed to ensure that grassroots politicians acquired prestige and community recognition for their commitment to CHPS, thereby catalyzing political support for the District Assembly process of committing development revenue to funding CHPS implementation. District level budgeting schemes were revised so that priorities could be shaped by prospects that strategies would optimize the impact of investment on the burden of disease, while engaging the political sector in the health budgeting process.

This investment in leadership development involved participatory task planning for orienting DHMT to the milestones and tasks for achieving healthcare in every community, with outreach to every doorstep, including community case management of childhood illness, cost-free maternal healthcare and treatment of childhood illness; comprehensive community-engaged referral services, with a deferred payment scheme for families confronting emergency logistics costs; and comprehensive and cost-free reproductive health services on demand.

Once GEHIP district health and political officials understood the CHPS implementation process, they contributed development revenue to construction activities based on CHPS infrastructural needs. This commitment was possible because of revenue from development mechanisms that are controlled by "District Chief Executives" and locally constituted "District Assemblies." In this manner, revenue was marshalled by collective engagement of health, local district and regional political and administrative authorities in budgetary review. Support for start-up costs of CHPS implementation and promotional activities was fostered by intersectoral engagement of representatives of the Ministries of Local Government, Food and Agriculture and Education. GEHIP-inspired multi-sectoral engagement led to earmarked revenue for CHPS capital investments, such as construction or equipment procurement.

To address the essential need for multi-sectoral financing of CHPS start-up, GEHIP engages with district health managers who invite political figures to CHPS community gatherings with the goal of engaging politician into the budget, financing and scaling-up process. When grassroots politicians witnessed popular support for CHPS, well-managed implementation events could translate implementation in a pilot locality into grassroots political investment in CHPS implementation elsewhere. By starting with pilot zones where this process can be demonstrated, CHPS start-up activities set the stage for community to community diffusion by providing intervention districts with $\$ 0.85$ per project year in supplemental funding, GEHIP could sponsor catalytic activities for fostering CHPS 
understanding and scale-up. District Assembly commitment for financing for CHPS facility and equipment costs.

The MOH review determined that CHPS meant different things to different stakeholders, despite concerted efforts directed to training, policy directives, conferences and reports. In its simplest formulation, the program was viewed by district health managers as a means of constructing community clinical facilities and posting nurses into these facilities and little else. Because health workers at all levels are accustomed to clinic-based work routines, instructions to relocate nurses to communities were interpreted through the prism of clinic managerial experience with health service delivery, as if community posting simply replicated sub-district clinical functions. Doorstep outreach, community organizational work, engagement of men and other social strategies of the Navrongo initiative were side-lined by the absorption of CHPS into the bureaucratic functions of a fixed facility clinical primary healthcare program.

Discussions with nurses illuminated concerns that attention to expanding the role of nurses as community-based providers and organizers would dilute service quality. CHPS priority on mobilizing and engaging the community in the health system was lost in the implementation process. Because of this, the necessary partnership among stakeholders-local government, communities, non-governmental organizations and development partners - and their shared participatory buy-in for CHPS never materialized because of contrasting understandings of the CHPS concept.

The GEHIP based its response to these problems on evidence from existing implementation research (Awoonor-Williams et al., 2004, 2010; Nyonator et al., 2011, 2005a, 2005b; Frimpong et al., 2013). In districts located elsewhere in Ghana, where CHPS has expanded rapidly, teams of service providers had experienced direct contact with the Navrongo or Nkwanta project operations. Implementation team exposure to functioning systems generated experience with implementation that could be shared by community implementers, their supervisors and district managers to implementation counterparts. Combined systems experience provided a basis for understanding CHPS implementation at each operational level. By cascading this implementation experience forward, with implementation in place in a few communities, district management teams could plan district-wide roll-out, guided by measurable progress indicators, budgets and peer learning that involves stakeholders at the district headquarter level and below. This political engagement process, originally developed in Navrongo and refined in Nkwanta, involves joint implementation of community mobilization "durbars" - a traditional function of chieftaincy systems in Ghana that is often co-opted by politicians during election campaigns to mobilize electoral support. But, as Navrongo and Nkwanta have demonstrated, health workers can also utilize such traditions for building community consensus and action that supports CHPS. Corporate institutions of lineage, social networks and chieftaincy can be aligned with political institutions and health systems engagement needs. By combining social systems, political systems and health delivery systems to revitalize CHPS, GEHIP has marshalled community demand for healthcare into Ghana's grassroots system of political accountability. 
This system of participatory CHPS knowledge management, focused on community engagement and systems learning, was crucial to building community commitment to scaling up CHPS in Nkwanta, and instrumental to catalyzing replication of CHPS scale-up elsewhere. But the formalization of the national CHPS scale-up agenda had drifted from this crucial "scaling down to scale-up" strategy (Nyonator et al., 2011). Indeed, participatory engagement strategies that work with CHPS have been critical to catalyzing scaling up elsewhere (Rosato et al., 2008).

Pursuing this multi-sectoral resource mobilization process for CHPS implementation process in the GEHIP intervention involved agile political engagement, community outreach and organizational savvy conducted by an experienced regional "CHPS coordinators" who trained district counterparts in essential liaison functions. Work routines, monitoring, budgeting, logistics and other routine management processes were altered to ensure consistent administrative leadership focusing on these requirements. The Regional Health Management Team provided the regional CHPS coordinator with time at monthly staff meetings to discuss activities, budgets, performance data and other routine implementation functions that catalyze the diffusion of lessons learned from successful CHPS implementation. CHPS monitoring and evaluation activities, and the visualization of CHPS coverage information were effective investments in support for evidence-based discussion of CHPS performance and problems. ${ }^{1}$ National leadership training initiatives have failed to fill this gap, however. Rather than to convene peer exchanges and provide catalytic financing for implementing pilot operations, the GHS has typically convened workshops for didactic training that disconnects CHPS leadership training from practical implementation-based management. GEHIP leadership development is a systems concept, however, with leadership extending from managers to supervisors, to workers and ultimately to the communities that are served.

\section{RESULTS}

The GEHIP initiative has aimed to overcome challenges to CHPS scale-up through replicable, affordable and sustainable mechanisms to strengthen leadership, partnership and community engagement. In addition, critical emergency referral services are now widely available, and the scope of care provided by frontline workers has been broadened to include a range of life-saving skills for mothers and newborns, especially the need to revisit the original Navrongo model for community-based primary healthcare while adding to that model elements that have been missing from CHPS in the past: (i) catalytic financing of only $\$ 0.85$ per capita per year in the primary healthcare program was combined with strategies for community-engaged celebration of implementation milestones; (ii) engaging traditional leaders and grassroots politicians in program implementation activities that incur prestige and community recognition for their commitment and leadership

\footnotetext{
${ }^{1}$ The monitoring process for tracking CHPS coverage is discussed by Nyonator et al. (2005a, 2011).
} 
with the goal of translating development revenue into funding for CHPS implementation; (iii) implementing healthcare in every community, with outreach to every doorstep, including community case management of childhood illness with mechanisms for ensuring community oversight of all service activities; (iv) providing cost-free maternal healthcare and treatment of childhood illness in conjunction with community-engaged referral services financed with a deferred payment scheme for emergency logistics costs; and (v) comprehensive and cost-free reproductive health services on demand. Taken as a package of activities and capabilities, GEHIP has accelerated CHPS coverage and achieved universal healthcare in the challenging context of the Upper East through the strategies outlined in Table 1.

The GEHIP's impact on the CHPS implementation process has been immediate and pronounced: starting from a low level of CHPS coverage when the program started in 2010 to September 2014, GEHIP achieved 82\% coverage of the total population with community service activities in treatment areas and corresponding to $100 \%$ of the targeted rural population reached by routine CHPS services in its four treatment districts within 4 years (Figure 3). Coverage also increased in comparison districts, starting at higher levels reached by CHPS in the baseline, but increasing at half the quarterly rate of scale-up, leading to $50 \%$ of the target population reached by September 2014. In treatment districts, GEHIP strategies have also improved the range and quality of primary healthcare services, with particular focus on maternal and newborn care and the development of sustainable referral services.

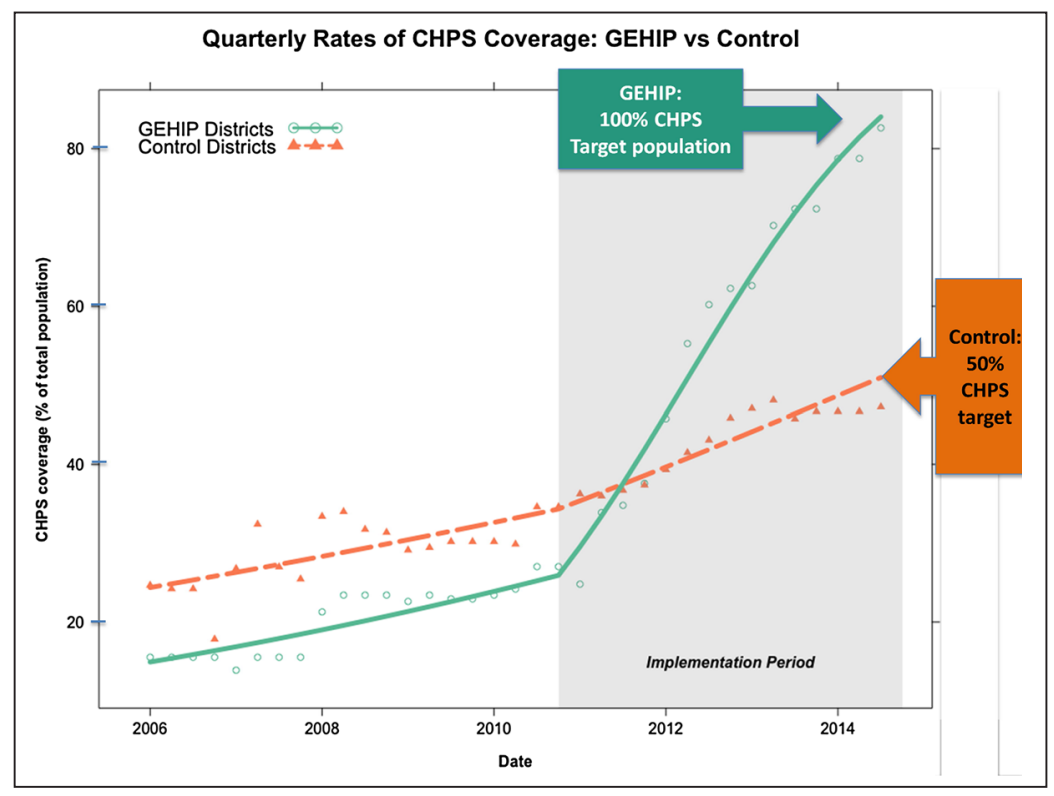

Figure 3. Quarterly rates of Community-based Health Planning and Services (CHPS) coverage: Ghana Essential Health Interventions Program (GEHIP) versus control 


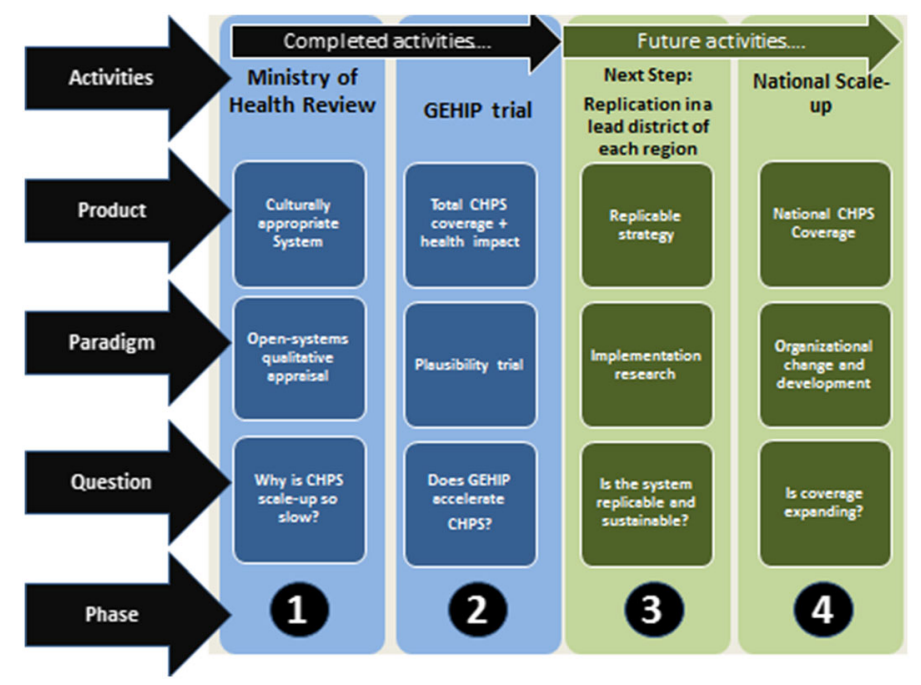

Figure 4. Phases for the experiment in improving and accelerating CHPS scale-up: the Ghana Essential Health Interventions Program (GEHIP)

\section{CONCLUSION}

Despite the challenges that have been identified, the CHPS initiative has begun to improve access to primary healthcare throughout Ghana. Its origins are grounded in evidence-based strategies for adapting implementation to local realities and needs. Yet CHPS scale-up has encountered implementation delays that require national corrective action. GEHIP implementation research results attest to the practicality of accelerating CHPS scale-up. While CHPS is a complex story, its core agenda is quite simple for stakeholders to understand and embrace if it is witnessed by implementation teams who have catalytic revenue for fostering scale-up and practical experience with grassroots social and political engagement. Achieving the transition from CHPS as it has evolved into a clinic-focused program into a fully people-centered and communityengaged program requires strategic attention, focus and simple-to-replicate action.

If CHPS succeeds at scale, it will have demonstrated mechanisms for bringing primary healthcare services to every Ghanaian household by aligning health sector policy, evidence and action, with vibrant systems of traditional leadership, communication and volunteerism. By demonstrating ways for CHPS to achieve its potential, GEHIP is not a project. Rather, it is the initial stage of a national program for strengthening community health systems in Ghana. The success of GEHIP is therefore a matter of considerable policy significance for Ghana.

Yet, just as CHPS represents a challenging initiative to implement at scale, systems strengthening activities in keeping with GEHIP will require strategic planning, replication monitoring and research, and evidence-based scaling up. We are therefore recommending a phased approach to GEHIP utilization that embraces scaling up lessons learned in the early stages of CHPS (as in Figure 1) with a new beginning that builds upon GEHIP success (Figure 4). In this perspective, the 
MOH review used qualitative systems appraisal to identify systems constraints to GEHIP scale-up and clarify needed action (phase 1, Figure 4). GEHIP has demonstrated that a process can be implemented for accelerating CHPS scale-up (phase 2, Figure 4). A new phase is now needed that will replicate GEHIP elsewhere in Ghana, starting with scale-up in the Upper East Region, but with concomitant activities in replication districts elsewhere in Ghana where the implementation requirements of large-scale utilization of the GEHIP approach can be tested, refined and used to develop national plans and learning localities. Milestones, resource allocation procedures and regional health administration roles and functions could be tested through "phase 3" GEHIP implementation research. Placing a GEHIP district in each of Ghana's nine other regions would set the stage for phasing in the utilization of GEHIP, positioning its lessons to become a solution to the need for rapid implementation of CHPS for all rural communities: a new "phase 4" for bringing community-based healthcare to every doorstep in Ghana.

\section{ACKNOWLEDGEMENTS}

The GEHIP is an initiative of the GHS that is supported by grants to the Mailman School of Public Health, Columbia University, from the Doris Duke Charitable Foundation Africa Health Initiative under grant number 2009058B and by grants to the University of Ghana School of Public Health by the British Charity Comic Relief.

The authors of this paper declare that they have no conflict of interest or financial interest arising from the direct application of this research.

\section{REFERENCES}

Adongo PB, Phillips JF, Baynes CB. 2014. Addressing men's concerns about reproductive health services and fertility regulation in a rural Sahelian setting of northern Ghana: The "Zurugelu Approach". In Critical Issues in Reproductive Health, Kulczycki A (ed). Springer Books Chapter 4: New York; 59-83.

Adongo PB, Phillips JF, Kajihara B, Fayorsey C, Debpuur C, Binka FN. 1997. Cultural factors constraining the introduction of family planning among the KassenaNankana of Northern Ghana. Soc Sci Med 45(12): 1789-1804. DOI:10.1016/S0277-9536(97)00110-X.

Adongo PB, Tapsoba P, Phillips JF, et al. 2013. The role of the Community-based Health Planning and Services Strategy in involving males in the provision of family planning services: A qualitative study in southern Ghana. Reproductive Health 10(36). DOI:10.1186/ 10.1186/1742-4755-10-36. Retrieved from http:// www.reproductive-health-journal.com/content/10/1/36

Awoonor-Williams JK, Bailey PE, Yeji F, Adongo AE, Baffoe P, Williams A, Mercer S. 2015. Conducting an audit to improve the facilitation of emergency maternal and newborn referral in Northern Ghana. Glob Public Health. DOI:10.1080/17441692.2015.1027247. Awoonor-Williams JK, Bawah AA, Nyonator FK, Asuru R, Oduro A, Ofosu A. 2013a. The Ghana Essential Health Interventions Programme: A plausibility trial of the impact of health systems strengthening on maternal \& child survival. BMC Health Serv Res 13(Suppl 2): S3. DOI:10.1186/1472-6963-13-S2-S3. Awoonor-Williams JK, Feinglass ES, Tobey R, et al. 2004. Bridging the gap between evidence-based innovation and national health-sector reform in Ghana. Stud Fam Plann 35(3): 161-177. Retrieved from http://www.ncbi.nlm.nih.gov/pubmed/15511060

Awoonor-Williams JK, Sory EK, Nyonator FK, Phillips JF, Wang C, Schmitt ML. 2013b. Lessons learned from scaling up a community-based health program in the Upper East Region of Northern Ghana. Global Health: Science and Practice 1(1): 117-133. DOI:10.9745/GHSP-D-12-00012. 


\section{J. K. AWOONOR-WILLIAMS ET AL.}

Awoonor-Williams JK, Sory EK, Phillips JF, Nyonator FK. 2013c. A case study in successful health system development in a challenging environment: rapid progress with scale-up of community-based primary health care in an impoverished region of Northern Ghana, 1-15.

Awoonor-Williams JK, Vaughan-Smith MN, Phillips JF. 2010. Scaling-up health system innovations at the community level: A case study of the Ghana experience. In Social Determinants of Sexual and Reproductive Health: Informing Future Research and Programme Implementation, Malarcher S (ed). World Health Organization: Geneva.

Baiden F, Hodgson A, Adjuik M, Adongo P, Bawah AA, Binka F. 2006. Trends and causes of neonatal mortality in the Kassena-Nankana district of northern Ghana, 1995-2002. Trop Med Int Health 11: 532-539. DOI:10.1111/j.1365-3156.2006.01582.x.

Bawah AA, Akweongo P, Simmons R, Phillips JF. 1999. Women's fears and men's anxieties: The impact of family planning on gender relations in Northern Ghana. Stud Fam Plann 30(1): 54-66. DOI:10.1111/ j.1728-4465.1999.00054.x.

Binka FN, Aikins M, Sackey SO, et al. 2009. In-depth Review of the Community-based Health Planning Services (CHPS) Programme: A Report of the Annual Health Sector Review, 2009. Ministry of Health, Republic of Ghana: Accra, Ghana.

Binka FN, Bawah AA, Phillips JF, Hodgson A, Adjuik M, Macleod BB. 2007. Rapid achievement of the child survival millennium development goal: evidence from the Navrongo experiment in Northern Ghana. Trop Med Int Health 12(5): 578-583. DOI:10.1111/j.13653156.2007.01826.x.

Binka FN, Nazzar KA, Phillips JF. 1995. The Navrongo Community Health and Family Planning Project. Stud Fam Plann 26: 121-139. DOI:10.2307/2137832.

Binswanger H, Aiyar S. 2003. Scaling Up Communitydriven Development: Theoretical Underpinnings and Programme Design Implications. The World Bank Africa Regional Office: Washington, DC.

Debpuur C, Phillips JF, Jackson EF, Nazzar KA, Ngom P, Binka FN. 2002. The impact of the Navrongo project on contraceptive knowledge and use, reproductive preferences, and fertility. Stud Fam Plann 33(2): 141-164. DOI:10.1111/j.1728-4465.2002.00141.x.

Freeman P, Perry HB, Gupta SK, Rassehk B, Rassehk B. 2009. Accelerating progress in achieving the millennium development goal for children through community-based approaches. Glob Public Health 7(4): 400-419. DOI:10.1080/17441690903330305.

Frimpong JA, Helleringer S, Awoonor-Williams JK, Aguilar T, Phillips JF, Yeji F. 2013. The complex association of health insurance and maternal health services in the context of a premium exemption for pregnant women: a case study in Northern Ghana. Health Policy Plan 29(1czt086): DOI:10.1093/heapol/ czt086.

Frimpong JA, Helleringer S, Awoonor-Williams JK, Yeji F, Phillips JF. 2011. Does supervision improve health worker productivity? Evidence from the Upper East Region of Ghana. Trop Med Int Health 16: 1225-1233. DOI:10.1111/j.1365-3156.2011.02824.x.

Knippenberg R, Levy-Bruhl D, Osseni R, Drame K, Soucat A, Debeugny C. 1990. The Bamako Initiative: primary health care. United Nations Childrens Fund (UNICEF): New York.

McCabe OL, Marum F, Semon N, et al. 2012. Participatory public health systems research: value of community involvement in a study series in mental health emergency preparedness. Am J Disaster Med 7(4): 303-312. DOI:10.5055/ajdm.2012.0103.

Ministry of Health, Republic of Ghana. 2009. Annual report. Accra, Ministry of Health, Republic of Ghana.

Nazzar KA, Adongo PB, Binka FN, Phillips JF, Debpuur C. 1995. Developing a culturally appropriate family planning program for the Navrongo experiment. Stud Fam Plann 26: 307-324.

Ngom P, Akweongo P, Adongo PB, Bawah AA, Binka FN. 1999. Maternal mortality among the Kassena-Nankana of Northern Ghana. Stud Fam Plann 30(2): 142-147. DOI:10.1111/j.1728-4465. 1999.00142.x.

Ngom P, Debpuur C, Akweongo P, Adongo P, Binka FN. 2003. Gate-keeping and women's health seeking behaviour in Navrongo, Northern Ghana. Afr J Reprod Health 7: 17-26.

Nyonator FK, Akosa AB, Awoonor-Williams JK, Phillips JF, Jones TC. 2008. Scaling up experimental project success with the Community-based Health Planning and Services initiative in Ghana. In Scaling Up Health Service Delivery: From Pilot Innovations to Policies and Programmes, Simmons R, Fajans P, Ghiron L. World Health Organization: Geneva; 89-112.

Nyonator FK, Awoonor-Williams JK, Phillips JF. 2011. Scaling Down to Scale-up: Accelerating the Expansion of Coverage of Community-based Health Services in Ghana. International Family Planning Conference, Dakar Senegal: Dakar, Senegal.

Nyonator FK, Awoonor-Williams JK, Phillips JF, Jones TC, Miller RA. 2005a. The Ghana Community-based Health Planning and Services initiative for scaling up service delivery innovation. Health Policy Plan 20(1): 25-34. DOI: 10.1093/heapol/czi003.

Nyonator FK, Jones TC, Miller RA, Phillips JF, Awoonor-Williams JK. 2005b. Guiding the Ghana Community-based Health Planning and Services approach to scaling up with qualitative systems appraisal. Int $Q$ Community Health Educ 23(3): 189-213. DOI:10.2190/NGM3-FYDT-5827-ML1P. 


\section{ACCELERATING COMMUNITY HEALTH CARE COVERAGE IN GHANA}

Pence BW, Nyarko P, Phillips JF, Debpuur C. 2007. The effect of community nurses and health volunteers on child mortality: the Navrongo Community Health and Family Planning Project. Scand $J$ Public Health 35(6): 599-608. DOI:10.1080/ 14034940701349225

Perry HB, Shanklin DS, Schroeder DG. 2003. Impact of a community-based comprehensive primary healthcare programme on infant and child mortality in Bolivia. $J$ Health Popul Nutr 21: 383-395.

Perry HB, Zulliger R, Rogers MM. 2014. Community health workers in low-, middle-, and high-income countries: an overview of their history, recent evolution, and current effectiveness. Annu Rev Public Health 35: 399-421. DOI: 10.1146/annurevpublhealth-032013-182354.

Phillips JF, Bawah AA, Binka FN. 2006. Accelerating reproductive and child health programme impact with community-based services: the Navrongo experiment in Ghana. Bull World Health Organ 84(12): 949-955. DOI: S0042-96862006001200010 [pii]

Rogers EM. 1962. The Diffusion of Innovations. The Free Press: New York, NY.
Rosato M, Laverack G, Grabman LHL, et al. 2008. Community participation: lessons for maternal, newborn, and child health. Lancet 372: 962-971.

Sarri R, Hasenfeld Y. 1978. Management of Human Services. Columbia University Press: New York, NY.

Simmons R, Shiffman J. 2005. Scaling-up reproductive health service innovations: a conceptual framework. In Scalingup Health Service Delivery: From Pilot Innovations to Policies and Programmes, Simmons R, Fajans P, Ghiron L. The World Health Organization: Geneva, Switzerland. World Bank. 2005. Improving Health, Nutrition and Population Outcomes in Sub-Saharan Africa: The Role of the World Bank. The World Bank: Washington, DC.

World Health Organization. 2005. Handbook IMCI: Integrated Management of Childhood Illness. World Health Organization: Geneva, Switzerland. Retrieved from http://books.google.com/books? $\mathrm{hl}=\mathrm{en} \& \mathrm{lr}=\& \mathrm{id}=4 \mathrm{Zhk} 4 \mathrm{Y} 6 \mathrm{U}$ shcC $\&$ pgis $=1$

World Health Organization. 2007. Everybody's Business: Strengthening Health Systems to Improve Health Outcomes: WHO's Framework for Action. World Health Organization. World Health Organization: Geneva, Switzerland. 